\title{
Clinical features in toxic coma in children
}

\author{
SIMONA STANCA ${ }^{1}$, CORIOLAN EMIL ULMEANU $^{2}$, HORIA TUDOR STANCA $^{3}$ and GHEORGHE IOVANESCU ${ }^{4}$ \\ ${ }^{1}$ Department of Pediatrics, 'Carol Davila' University of Medicine and Pharmacy, 'Grigore Alexandrescu' \\ Clinical Emergency Hospital for Children; Departments of ${ }^{2}$ Pediatrics and ${ }^{3}$ Ophthalmology, \\ 'Carol Davila' University of Medicine and Pharmacy, 050474 Bucharest; \\ ${ }^{4}$ Department of ENT, 'Victor Babes' University of Medicine and Pharmacy, 300041 Timisoara, Romania
}

Received May 30, 2019; Accepted July 25, 2019

DOI: $10.3892 /$ etm.2019.7857

\begin{abstract}
The purpose was to identify rapidly the etiology of toxic coma in children, to appreciate the severity of the coma, to detect elements of gravity based on associated clinical signs and symptoms and to evaluate the initial treatment. Toxic coma is a medical emergency, especially in a Pediatric Emergency Department, requiring rapid and precise evaluation. The key objectives in the evaluation and management of coma in children are: detecting severity characteristics, depth of coma, specific clinical signs and symptoms, etiological and differential diagnostic and also initializing supportive therapy and specific treatment. This is a retrospective study, where we analyzed all patients diagnosed with coma admitted to the 'Grigore Alexandrescu' Clinical Emergency Hospital for Children over a nine-year period from 2003 to 2011. We focused on toxic coma. A prospective component related to tracking certain signs and symptoms associated with toxic coma to diagnose and initiate appropriate therapy as early as possible was also included. In this nine-year study, 750 comatose patients were included. We found that toxicants represent the main cause of coma in children. There were 445 patients diagnosed with toxic coma, representing $59.3 \%$ and 305 cases of non-toxic coma, $40.7 \%$ of all coma cases presented in ER. The etiology of toxic coma in children is dominated by alcohol and abuse substances, followed by neurologic medication. Clinical manifestations were more frequent and more severe as the coma degree increases. Associating clinical manifestations in patients with altered neurologic status of toxic cause and toxicants has an important role in practice, because it helps us recognize the frequency of association of coma complications such as: aspiration syndrome, arrhythmias and seizures.
\end{abstract}

Correspondence to: Dr Horia Tudor Stanca, Department of Ophthalmology, 'Carol Davila' University of Medicine and Pharmacy, 8 Bd. Eroilor Sanitari, Sector 5, 050474 Bucharest, Romania E-mail: hstanca@yahoo.com

Key words: coma in children, clinical signs, poisoning, triage, emergency

\section{Introduction}

Toxic comas represent neurologic emergencies that require immediate evaluation and therapeutic intervention; therefore, considering the first hour is crucial, it is necessary to use specific algorithms (protocols). The first evaluation of the comatose child and the first therapeutic measures are initiated at the same time, as soon as possible (1). Therefore, these children require stabilization of vital functions, because at this stage it is difficult to identify etiology $(2,3)$.

Poisoning constitutes a dynamic condition and may have unpredictable evolution, especially in children. Consciousness and the patient's ability to maintain a patent airway and proper ventilation can change rapidly, so it is important to anticipate the action of the involved toxic $(4,5)$.

The objective was to rapidly identify the etiology of toxic coma in children, to appreciate the severity of the coma, to detect elements of gravity based on associated clinical signs and symptoms, in order to establish and initiate an effective treatment.

\section{Patients and methods}

This is a retrospective study, in which we analyzed all patients diagnosed with coma admitted to the 'Grigore Alexandrescu' Clinical Emergency Hospital for Children in Bucharest (Romania) over a nine-year period (2003-2011). This study adhered to the tenets of the Declaration of Helsinki and was approved by the Ethics Committee of our hospital, 'Grigore Alexandrescu' Clinical Emergency Hospital for Children. Focus was on toxic coma also including a prospective component related to tracking certain signs and symptoms associated with toxic coma to diagnose and initiate appropriate therapy as early as possible.

In order to assess the depth of the coma, the Reed scale, with 4 degrees was used.

The 1st degree coma patients included were those with dysarthria, reaction to pain stimuli and reflex responses present. Patients with 2 nd degree coma are unresponsive to verbal stimulation and pain stimuli; they also present reflex responses. Patients unresponsive to verbal or pain stimulation, with diminished reflexes and vital functions present, were classified as 3rd degree coma patients. Non-reactive and unstable patients were included in 4th degree of coma - deep coma $(6,7)$. 
Table I. Cases of poisoning, coma and deaths between 2003 and 2011.

\begin{tabular}{lccccc}
\hline Year & Poisoning & Toxic coma & Toxic coma $(\%)$ & Deaths & Deaths in toxic coma (\%) \\
\hline 2003 & 663 & 20 & 3.01 & 2 & 10 \\
2004 & 615 & 42 & 6.82 & 3 & 7.14 \\
2005 & 529 & 32 & 6.04 & 3 & 9.37 \\
2006 & 570 & 37 & 6.49 & 5 & 13.5 \\
2007 & 518 & 45 & 8.68 & 1 & 2.22 \\
2008 & 634 & 58 & 9.10 & 2 & 3.44 \\
2009 & 726 & 62 & 8.50 & 2 & 3.22 \\
2010 & 718 & 71 & 9.80 & 3 & 4.22 \\
2011 & 788 & 78 & 9.89 & 2 & 2.56 \\
Total & 5761 & 445 & 7.72 & 23 & 5.16 \\
\hline
\end{tabular}

Table II. Etiology of toxic coma in children.

\begin{tabular}{lccc}
\hline Etiology & Frequency & Percentage & Cumulative percentage \\
\hline Ethanol/Abuse substances & 213 & 47.9 & 47.9 \\
CNS acting drugs & 67 & 15.1 & 62.9 \\
Unknown & 57 & 12.8 & 75.7 \\
Non-pharmacological substances & 47 & 10.6 & 86.3 \\
Multiple drug poisoning & 35 & 7.9 & 94.2 \\
Dentocalmin (lidocaine, menthol, phenol solution) & 21 & 4.7 & 98.9 \\
Isoniazid & 5 & 1.1 & 100.0 \\
Total & 445 & 100.0 & \\
\hline
\end{tabular}

Blood pressure, respiratory rate and pulse rate in children are specific for different age groups. Therefore, reports were made using reference values for age groups (8-10).

Statistical analysis. The IBM SPSS v20 has been used to verify hypotheses. The descriptive analysis used media, median, modal value, standard error of average and standard deviation. Statistical results of $<0.05$ ( $\mathrm{p}$ wave) and a confidence interval of $95 \%$ were considered to indicate a statistically significant difference. The relative risk and OR were verified using tests such as Student's t-test, Chi-square test, Fischer exact test and ANOVA. A Games Howell post hoc test has been run, as the data did not meet the homogeneity of variances assumption. Binary logistic regression was used to check the share of each risk factor in the chosen model.

\section{Results and Discussion}

In this nine-year study (2003-2011) 750 comatose patients were included; they were admitted to Pediatric Emergency Department of the 'Grigore Alexandrescu' Clinical Emergency Hospital for Children. We found that toxicants represent the main cause of coma in children. There were 445 patients diagnosed with toxic coma, representing 59.3\% and 305 cases of non-toxic coma, $40.7 \%$ of all coma cases presented in the ER (Table I).

It was noted that the etiology of toxic coma in children is dominated by alcohol and abuse of substances: $47.9 \%$, followed by poisoning with drugs acting on the central nervous system: $15.1 \%$. Coma caused by non-pharmacological substances represents $10.6 \%$ of the total of toxic comas in children. Multidrug poisoning in $7.9 \%$ of the etiology was found. In total, 57 remained of unknown origin, representing $12.8 \%$. In addition, the following should be mentioned: Dentocalmin, which is a combination of lidocaine, menthol and phenol, generating severe poisoning - all accidental, and isoniazid, commonly used in medical practice for tuberculosis treatment, all suicidal attempts (Table II).

Establishing different associations between these features enabled us to relate coma scale degrees with clinical manifestations (Table III).

The 1st degree coma was associated with vomiting in $53.3 \%$ of the cases; aspiration syndrome in $1.6 \%$; arrhythmias in $2.1 \%$; cold, marbled, cyanotic extremities in $34 \%$; capillary refill time over $3 \mathrm{sec}$ in $11.9 \%$; hypothermia in $3.8 \%$ and hyperthermia in $1 \%$; myosis in $7.5 \%$ and mydriasis in $5.9 \%$; seizures in $3.2 \%$ and convulsive status in $0.5 \%$ of the cases.

The 2nd degree coma was associated with vomiting in $72.8 \%$ of the cases; aspiration syndrome in $1.5 \%$; arrhythmias in $6.5 \%$; cold, marbled, cyanotic extremities in $74.3 \%$ of the cases; capillary refill time over $3 \mathrm{sec}$ in $41 \%$; hypothermia in $11.5 \%$ and hyperthermia in $1 \%$ of the cases; myosis in $10 \%$ and mydriasis in $14 \%$ of the cases; seizures in $16 \%$ and convulsive status in $1.5 \%$ of the cases. 
Table III. Association between clinical findings and the depth of coma.

\begin{tabular}{|c|c|c|c|c|c|c|c|c|}
\hline \multirow{3}{*}{$\begin{array}{l}\text { Clinical signs and symptoms } \\
\text { in toxic coma }\end{array}$} & \multicolumn{8}{|c|}{ Coma degree } \\
\hline & \multicolumn{2}{|c|}{1} & \multicolumn{2}{|c|}{2} & \multicolumn{2}{|c|}{3} & \multicolumn{2}{|c|}{4} \\
\hline & No. & $\%$ & No. & $\%$ & No. & $\%$ & No. & $\%$ \\
\hline \multicolumn{9}{|l|}{ Vomiting } \\
\hline No & 86 & 19.3 & 54 & 12.1 & 18 & 4 & 3 & 0.7 \\
\hline Yes & 99 & 22.2 & 145 & 32.6 & 34 & 7.6 & 6 & 1.3 \\
\hline \multicolumn{9}{|l|}{ Aspiration syndrome } \\
\hline No & 182 & 40.9 & 196 & 44 & 51 & 11.5 & 5 & 1.1 \\
\hline Yes & 3 & 0.7 & 3 & 0.7 & 1 & 0.2 & 4 & 0.9 \\
\hline \multicolumn{9}{|l|}{ Arrhythmias } \\
\hline No & 180 & 40.5 & 186 & 41.9 & 30 & 6.8 & 4 & 0.9 \\
\hline Yes & 4 & 0.9 & 13 & 2.9 & 22 & 5 & 5 & 1.1 \\
\hline \multicolumn{9}{|l|}{ Extremities } \\
\hline Normal & 121 & 27.2 & 51 & 11.5 & 0 & 0.0 & 0 & 0 \\
\hline Cold, marble, cyanotic & 63 & 14.2 & 148 & 33.3 & 52 & 11.7 & 9 & 2 \\
\hline \multicolumn{9}{|l|}{ Capillary refill time } \\
\hline$<3 \mathrm{sec}$ & 163 & 36.6 & 116 & 26.1 & 3 & 0.7 & 0 & 0 \\
\hline$>3 \mathrm{sec}$ & 22 & 4.9 & 83 & 18.7 & 49 & 11 & 9 & 2 \\
\hline \multicolumn{9}{|l|}{ Temperature } \\
\hline Normal & 176 & 39.6 & 174 & 39.1 & 37 & 8.3 & 7 & 1.6 \\
\hline Hyperthermia & 2 & 0.4 & 2 & 0.4 & 1 & 0.2 & 0 & 0 \\
\hline Hypothermia & 7 & 1.6 & 23 & 5.2 & 14 & 3.1 & 2 & 0.4 \\
\hline \multicolumn{9}{|l|}{ Pupillary size } \\
\hline Normal & 160 & 36 & 151 & 33.9 & 19 & 4.3 & 3 & 0.7 \\
\hline Mydriasis & 11 & 2.5 & 28 & 6.3 & 16 & 3.6 & 5 & 1.1 \\
\hline Myosis & 14 & 3.1 & 20 & 4.5 & 17 & 3.8 & 1 & 0.2 \\
\hline \multicolumn{9}{|l|}{ Seizures } \\
\hline No & 178 & 40 & 163 & 36.6 & 32 & 7.2 & 3 & 0.7 \\
\hline Yes & 6 & 1.3 & 33 & 7.4 & 16 & 3.6 & 4 & 0.9 \\
\hline Convulsive status & 1 & 0.2 & 3 & 0.7 & 4 & 0.9 & 2 & 0.4 \\
\hline
\end{tabular}

The 3rd degree coma was associated with vomiting in $65 \%$ of the cases; aspiration syndrome in $1.9 \%$; arrhythmias in $42 \%$; cold, marbled, cyanotic extremities in $100 \%$; capillary refill time over $3 \mathrm{sec}$ in $94 \%$; hypothermia in $26.9 \%$ and hyperthermia in $1.9 \%$; myosis in $32.6 \%$ and mydriasis in $30.7 \%$; seizures in $16 \%$ and convulsive status in $7.6 \%$ of the cases.

The 4th degree coma was associated with vomiting in $65 \%$ of the cases; aspiration syndrome in 44\%; arrhythmias in 55\%; cold, marbled cyanotic extremities in $100 \%$; capillary refill time over $3 \mathrm{sec}$ in 100\%; hypothermia in $22 \%$; myosis in $11 \%$ and mydriasis in $55 \%$; seizures in $44 \%$ and convulsive status in $22 \%$ of the cases.

The clinical manifestations described above were more frequent and more severe as the coma degree increased. Life threatening symptoms, such as arrhythmias and seizures or even convulsive status and aspiration syndrome were present in 55.5, 44.4, 22.2 and $44.4 \%$, respectively, of the cases for 4th degree coma, compared to $2.1,3.2,0.5$ and $1.6 \%$ of the cases in 1st degree coma.
A great challenge was to establish a significant association between the clinical signs and the etiology of toxic coma, as shown in Table IV.

Significant conclusions were drawn after associating clinical manifestations in patients with altered neurologic status of toxic cause and toxicants.

Vomiting was present in $93.6 \%$ of the cases in toxic coma produced by non-pharmacological substances, in $80 \%$ of the cases in isoniazid-related coma, in $71 \%$ of the cases in multidrug-related coma, in $64.7 \%$ of the cases in alcohol and abuse substances-induced coma, in $52.2 \%$ of the cases of toxic coma by neurological medication and in 19\% cases of Dentocalmin-induced coma. Vomiting was present in 59.6\% of cases of unknown etiology coma.

Aspiration syndrome was present in $24.7 \%$ of toxic coma cases. Regarding the coma scale, we observed that in three cases, the coma degree was 1 ; in one case, the coma degree was 3 and in four cases, the coma degree was 4 . Differences were observed when we related coma to etiology. Aspiration 
Table IV. Association between coma and other clinical signs according to etiology.

\begin{tabular}{|c|c|c|c|c|c|c|c|c|c|c|c|c|c|c|}
\hline \multirow{3}{*}{$\begin{array}{l}\text { Clinical signs associated } \\
\text { to toxic coma }\end{array}$} & \multicolumn{14}{|c|}{ Etiology } \\
\hline & \multicolumn{2}{|c|}{$\begin{array}{l}\text { CNS } \\
\text { drugs }\end{array}$} & \multicolumn{2}{|c|}{$\begin{array}{l}\text { Alcohol/ } \\
\text { abuse } \\
\text { substances }\end{array}$} & \multicolumn{2}{|c|}{$\begin{array}{l}\text { Non-pharma- } \\
\text { cological } \\
\text { substances }\end{array}$} & \multicolumn{2}{|c|}{ Isoniazid } & \multicolumn{2}{|c|}{$\begin{array}{l}\text { Dentocalmin } \\
\text { (lidocaine sol) }\end{array}$} & \multicolumn{2}{|c|}{ Multidrug } & \multicolumn{2}{|c|}{ Unknown } \\
\hline & No. & $\%$ & No. & $\%$ & No. & $\%$ & No. & $\%$ & No. & $\%$ & No. & $\%$ & No. & $\%$ \\
\hline \multicolumn{15}{|l|}{ Vomiting } \\
\hline No & 32 & 7.2 & 75 & 16.9 & 3 & 0.7 & 1 & 0.2 & 17 & 3.8 & 10 & 2.2 & 23 & 5.2 \\
\hline Yes & 35 & 7.9 & 138 & 31 & 44 & 9.9 & 4 & 0.9 & 4 & 0.9 & 25 & 5.6 & 34 & 7.6 \\
\hline \multicolumn{15}{|l|}{ Aspiration syndrome } \\
\hline No & 66 & 14.8 & 211 & 47.4 & 39 & 8.8 & 5 & 1.1 & 21 & 4.7 & 35 & 7.9 & 57 & 12.8 \\
\hline Yes & 1 & 0.2 & 2 & 0.4 & 8 & 1.8 & 0 & 0 & 0 & 0 & 0 & 0 & 0 & 0 \\
\hline \multicolumn{15}{|l|}{ Arrhythmias } \\
\hline No & 54 & 12.2 & 211 & 47.5 & 33 & 7.4 & 5 & 1.1 & 9 & 2 & 34 & 7.7 & 54 & 12.2 \\
\hline Yes & 13 & 2.9 & 2 & 0.5 & 13 & 2.9 & 0 & 0 & 12 & 2.7 & 1 & 0.2 & 3 & 0.7 \\
\hline \multicolumn{15}{|l|}{ Extremities } \\
\hline Normal & 26 & 5.8 & 103 & 23.1 & 7 & 1.6 & 1 & 0.2 & 0 & 0 & 11 & 2.5 & 24 & 5.4 \\
\hline Cold, cyanotic, marbled & 41 & 9.2 & 110 & 24.7 & 39 & 8.8 & 4 & 0.9 & 21 & 4.7 & 24 & 5.4 & 33 & 7.4 \\
\hline \multicolumn{15}{|l|}{ Capillary refill time } \\
\hline$<3 \mathrm{sec}$ & 39 & 8.8 & 160 & 36 & 12 & 2.7 & 1 & 0.2 & 5 & 1.1 & 21 & 4.7 & 44 & 9.9 \\
\hline$>3 \mathrm{sec}$ & 28 & 6.3 & 53 & 11.9 & 35 & 7.9 & 4 & 0.9 & 16 & 3.6 & 14 & 3.1 & 13 & 2.9 \\
\hline \multicolumn{15}{|l|}{ Temperature } \\
\hline Normal & 63 & 14.2 & 177 & 39.8 & 44 & 9.9 & 4 & 0.9 & 21 & 4.7 & 31 & 7.0 & 54 & 12.1 \\
\hline Hyperthermia & 1 & 0.2 & 1 & 0.2 & 1 & 0.2 & 1 & 0.2 & 0 & 0 & 0 & 0 & 1 & 0.2 \\
\hline Hypothermia & 3 & 0.7 & 35 & 7.9 & 2 & 0.4 & 0 & 0 & 0 & 0 & 4 & 0.9 & 2 & 0.4 \\
\hline \multicolumn{15}{|l|}{ Pupillary diameter } \\
\hline Normal & 27 & 6.1 & 192 & 43.1 & 31 & 7.0 & 2 & 0.4 & 13 & 2.9 & 29 & 6.5 & 39 & 8.8 \\
\hline Mydriasis & 23 & 5.2 & 17 & 3.8 & 1 & 0.2 & 3 & 0.7 & 8 & 1.8 & 1 & 0.2 & 7 & 1.6 \\
\hline Myosis & 17 & 3.8 & 4 & 0.9 & 15 & 3.4 & 0 & 0 & 0 & 0 & 5 & 1.1 & 11 & 2.5 \\
\hline \multicolumn{15}{|l|}{ Seizures } \\
\hline Absent & 55 & 12.4 & 205 & 46.1 & 28 & 6.3 & 1 & 0.2 & 6 & 1.3 & 31 & 7 & 50 & 11.2 \\
\hline Present & 12 & 2.7 & 8 & 1.8 & 16 & 3.6 & 2 & 0.4 & 10 & 2.2 & 4 & 0.9 & 7 & 1.6 \\
\hline Convulsive status & 0 & 0 & 0 & 0 & 3 & 0.7 & 2 & 0.4 & 5 & 1.1 & 0 & 0 & 0 & 0 \\
\hline
\end{tabular}

syndrome was present in 8 cases of non-pharmacological substance toxic coma, a total of $17 \%$, and also in 2 cases of poisoning with alcohol and abuse substances $(0.9 \%)$ and one case of coma was related to CNS drug poisoning (1.49\%). Aspiration syndrome was not associated with coma in multidrug, isoniazid, Dentocalmin or unknown substance poisoning.

Coma associated with arrhythmias represented 9.8\% of total cases. Distribution according to coma etiology was as follows: $19.4 \%$ cases of coma in CNS drug poisoning associated arrhythmias and only $0.9 \%$ cases of alcoholic and abuse substances coma associated arrhythmias. Non-pharmacological substance poisoning associated coma and arrhythmias were present in $27.6 \%$ cases. Dentocalmin produced severe poisoning features manifested not only with altered mental status, but also with arrhythmias in $57.1 \%$ of the cases.
Hypothermia was recorded in $10.3 \%$ of the cases. Most cases of hypothermia were associated with alcohol poisoning: $16.4 \%$ in all coma cases. In addition, $4.4 \%$ of patients with coma induced by CNS drugs were hypothermic upon presentation.

In $25 \%$ of the cases of CNS drug poisoning coma, myosis was present, with $34 \%$ of the cases of mydriasis, so a total of $59 \%$ cases of coma associated with pupillary diameter abnormality. Seizures were present in $13.2 \%$ of cases of toxic coma, $17.9 \%$ cases of coma by CNS drug associated seizures and $3.75 \%$ cases of alcohol and abuse substances coma associated seizures. Non-pharmacological substance poisoning coma-associated seizures were present in $34 \%$ of the cases, and in $6 \%$ of cases in convulsive status. Two out of five cases of isoniazid poisoning developed seizures (40\%) and other two developed convulsive status, with a total of $80 \%$ of cases with paroxysmal manifestation. Seizures in Dentocalmin poisoning 
Table V. Age average according to the degree of coma.

$95 \%$ confidence

interval for mean

\begin{tabular}{lrccccccc} 
Coma degree & No. & Age average & SD & SE & Lower bound & Upper bound & Minimum & Maximum \\
\hline 1 & 185 & 11.71 & 4.917 & 0.361 & 10.99 & 12.42 & 0 & 17 \\
2 & 199 & 11.01 & 5.272 & 0.374 & 10.27 & 11.75 & 0 & 18 \\
3 & 52 & 8.94 & 5.988 & 0.830 & 7.28 & 10.61 & 0 & 17 \\
4 & 9 & 7.67 & 5.723 & 1.908 & 3.27 & 12.07 & 1 & 15 \\
Total & 445 & 10.99 & 5.297 & 0.251 & 10.50 & 11.48 & 0 & 18
\end{tabular}

SD, standard deviation; SE, standard error.

Table VI. Distribution of cases by the depth of coma.

\begin{tabular}{lcc}
\hline & \multicolumn{2}{c}{ Total } \\
\cline { 2 - 3 } Coma degree & No. & $\%$ \\
\hline 1 & 185 & 41.6 \\
2 & 199 & 44.7 \\
3 & 52 & 11.7 \\
4 & 9 & 2 \\
Total & 445 & 100 \\
\hline
\end{tabular}

were present in $47.6 \%$ of the cases and convulsive status was recorded in $23.8 \%$ of the cases (a total of $71.4 \%$ ). The association between multidrug poisoning and seizures was recorded in $11.4 \%$ of the cases and in $12.2 \%$ of the cases of unknown toxicant poisoning.

Clinical examination of patients at presentation revealed normal looking extremities in $38.6 \%$ of the cases, cold, marbled, cyanotic extremities in $61.4 \%$ of the cases. Capillary refill time was normal in $62.7 \%$ of the cases and prolonged in $37.3 \%$ of the cases. Regulation of blood flow in extremities is realized by central and peripheral mechanisms: Hypoventilation (respiratory toxic drugs) or unventilated pulmonary areas (hydrocarbon aspiration pneumonia), cutaneous vasoconstriction (hypothermia or increased peripheral vascular resistance due to poisoning), decreased oxygen transportation mechanism (nitrites poisoning) and is impaired in poisoning complicated with shock $(11,12)$.
An interesting statistical association is represented by the age average according to the degree of coma using the Reed scale (Table V).

In the studied group, we found that the degree of coma is inversely proportional to the age average, so the deeper the coma, the lower the average age.

The distribution of cases by coma degree is as follows: 185 cases of 1 st degree, representing $41.6 \%$ of all toxic coma, with an average age of 11.7 years; 199 cases of 2nd degree (44.7\%), with a mean age of 11 years; 52 cases of 3rd degree (11.6\%), with an average age of 8.9 years and 9 cases of coma degree 4 (representing 2\%) with 7.6 age average (Table VI).

We made the null hypothesis that there are no age differences between the degrees of coma (Table VII).

By applying statistical significance tests (ANOVA variant analysis assay), the null hypothesis is denied for a statistical probability of $<0.05$, which means that the age average differs significantly between the four coma degrees.

This statistical analysis has an important role in practice, because it helps us identify the frequency of association of coma complications, such as aspiration syndrome, arrhythmias and seizures with the severity of the coma.

In a study published in 2018 , conducted in a tertiary care hospital in Iasi, in Northeast Romania, we found data similar to those in the present study. The study group consisted of 69 patients, aged 2 to 17, 36 boys (52.2\%) and 33 (47.8\%) girls. The main cause of coma in patients that required hospitalization and treatment in a medical intensive care unit was ethanol, $52.2 \%$ of the cases. In two patients, ethanol combined with ethnobotanics induced coma. Others causes of coma were drugs, $31.9 \%$ of the cases, organophosphorus insecticide in 6 cases, mushrooms in 2 cases, carbon monoxide, diluent,

Table VII. Age differences between the degrees of coma.

\begin{tabular}{lcccr}
\hline Groups & Sum of squares & df & Mean square & F-value \\
\hline Between groups & 412.919 & 3 & 137.640 & 5.040 \\
Within groups & 12043.045 & 441 & 27.308 & 0.002 \\
Total & 12455.964 & 444 & & \\
\hline
\end{tabular}

ANOVA, the test shows that age average differs between the 4 degrees of coma. df, degrees of freedom. 
marijuana, 1 case each. Most of the patients with ethanolic and drugs induced coma had psychological and social problems, $73 \%$. The youngest child with ethanolic coma was 2 years old. Among drugs, benzodiazepine overdose induced-coma was present in $18.6 \%$ of the patients, and 4 patients presented coma post ingestion of multiple neuroleptic and anticonvulsant drugs. Only $17.4 \%$ of the patients required orotracheal intubation (13). The evolution was favorable in most cases; only two deaths were registered (3\%) (14).

In conclusion, the etiology of toxic coma in children was dominated by alcohol and abuse substances in $47.9 \%$ of the cases, followed by neurologic medication in $15.1 \%$ of the cases. Coma induced by non-pharmacological substances represents a total of $10.6 \%$ cases, but has a higher severity and mortality rate. $7.9 \%$ cases of toxic coma had multidrug etiology. In total, 57 cases remain of unknown toxicant etiology; poisoning substance could not be identified in a total of $12.8 \%$ of the cases.

Clinical manifestations associated with toxic coma were more frequent and more severe as the degree of mental status alteration increased. Life threatening events such as arrhythmias, seizures and convulsive status or aspiration syndrome were present in $55.5 \%, 44.4 \%, 22.2 \%$ and $44.4 \%$ of the cases, respectively, for 4th degree Reed coma scale and 2.1, 3.2, 0.5 and $0.6 \%$ of cases in 1st degree Reed coma scale.

Associating clinical manifestations in patients with altered neurologic status of toxic cause and toxicants has an important role in practice, because it helps us identify the frequency of association of coma complications, such as aspiration syndrome, arrhythmias and seizures.

\section{Acknowledgements}

Professional editing, linguistic and technical assistance performed by Individual Service Provider Irina Radu, certified translator in Medicine and Pharmacy.

\section{Funding}

No funding was received.

\section{Availability of data and materials}

All data generated or analyzed during this study are included in this published article.

\section{Authors' contributions}

SS contributed substantially to the conception and design of the study. CEU contributed substantially to the design of the study. SS, HTS and GI contributed to the acquisition, analysis and interpretation of data. SS, CEU, HTS and GI were involved in the drafting of the study and SS and HTS in revising the study critically for important intellectual content. All authors read and approved the final version of the study and agreed to be accountable for all aspects of the work in ensuring that questions related to the accuracy or integrity of any part of the work are appropriately investigated and resolved.

\section{Ethics approval and consent to participate}

This study adhered to the tenets of the Declaration of Helsinki and was approved by the Ethics Committee of our hospital, 'Grigore Alexandrescu' Clinical Emergency Hospital for Children (Bucharest, Romania).

\section{Patient consent for publication}

Not applicable.

\section{Competing interests}

The authors declare that they have no competing interests.

\section{References}

1. Nichols DG and Cantwell GP: Roger's Textbook of Pediatric Intensive Care. 31st edition. pp441-464, 2008.

2. Daly FF, Little M and Murray L: A risk assessment based approach to the management of acute poisoning. Emerg Med J 23: 396-399, 2006.

3. Abend NS, Kessler SK, Helfaer MA and Licht DJ: Evaluation of the comatose child. In: Rogers' Textbook of Pediatric Intensive Care. 4th edition. Abend NS (ed). Lippincot Williams \& Wilkins, Philadelphia, pp846-847, 2008.

4. Stanca S, Petran M, Ulmeanu C and Nitescu V: Toxic coma in children - etiology and clinical diagnosis. Therapeutics. Pharmacol Clin Toxicol 15: 51-55, 2011.

5. World Health Organisation: International Statistical classification of Diseases and Related Health Problems. 10th revision, ICD-10. WHO, Geneva, 1992.

6. Stack C and Dobbs P: Trauma. Essentials of Paediatric Intensive Care Cambridge University Press, pp156-157, 2008.

7. Behrman RE, Kliegman R and Jenson HB: Nelson Textbook of Pediatrics. 16th edition. WB Saunders Co., Philadelphia, 2000.

8. Caruntu C, Boda D, Dumitrascu G, Constantin C and Neagu M: Proteomics focusing on immune markers in psoriatic arthritis. Biomarkers Med 9: 513-528, 2015.

9. Solomon I, Voiculescu VM, Caruntu C, Lupu M, Popa A, Ilie MA, Albulescu R, Caruntu A, Tanase C, Constantin C, et al: Neuroendocrine factors and head and neck squamous cell carcinoma: An affair to remember. Dis Markers 2018: 9787831, 2018.

10. Ion A, Popa IM, Papagheorghe LML, Lisievici C, Lupu M, Voiculescu V, Caruntu C and Boda D: Proteomic approaches to biomarker discovery in cutaneous T-cell lymphoma. Dis Markers 2016: 9602472, 2016.

11. Lupu M, Caruntu A, Caruntu C, Papagheorghe LM, Ilie MA, Voiculescu V, Boda D, Constantin C, Tanase C, Sifaki M, et al: Neuroendocrine factors: The missing link in non-melanoma skin cancer (Review). Oncol Rep 38: 1327-1340, 2017.

12. Batani A, Brănișteanu DE, Ilie MA, Boda D, Ianosi S, Ianosi G and Caruntu C: Assessment of dermal papillary and microvascular parameters in psoriasis vulgaris using in vivo reflectance confocal microscopy. Exp Ther Med 15: 1241-1246, 2018.

13. Balica NC, Poenaru M, Doroş CI, Baderca F, Preda MA, Iovan VC, Stanca HT, Busuioc CJ, Oprişcan IC and Boruga O: The management of the oropharyngeal anterior wall cancer. Rom J Morphol Embryol 59: 113-119, 2018.

14. Frasinariu $\mathrm{O}$ and Streanga V: Toxic coma in a medical intensive care unit. In: Proceedings of the 7th Congress of the European Academy of Paediatric Societies. EAP, ESPNIC and ESPR, Paris, 2018. https://eaps.kenes.com/2018.

This work is licensed under a Creative Commons Attribution-NonCommercial-NoDerivatives 4.0 International (CC BY-NC-ND 4.0) License. 